\title{
A corporação cristã em perspectiva transnacional: interações e transferências entre as organizações católicas para trabalhadores de Camaragibe (Brasil) e Val-des-Bois (França)
}

The Christian corporation in a transnational perspective: Interactions and Transfers Between Catholic Organizations for Workers in Camaragibe (Brazil) and Val-des-Bois (France)

\section{Deivison Gonçalves Amaral*}

Resumo: O artigo analisa as interações e transferências transnacionais entre corporações operárias confessionais e o ativismo de leigos católicos, especialmente de empresários, entre Brasil e França. Busca especialmente entender as conexões do militante Carlos Alberto de Menezes, de Pernambuco, com Léon Harmel, de Valdes-Bois, França, na última década do século XIX e primeira do século XX. Especial atenção é dada ao modelo de corporação cristã e à cultura do bon patron que Menezes aprendeu com Harmel, trouxe ao Brasil, adaptou e recriou em Camaragibe.

Palavras-chave: Corporação cristã; Catolicismo social; associativismo; história do trabalho; história transnacional.

Abstract: This article analyses interactions and transfers between Brazilian and French confessional labour corporations and catholic laymen, mainly entrepreneurs. It is of particular interest to understand the connections of the militant and entrepreneur Carlos Alberto de Menezes, from Camaragibe, Brazil, and Léon Harmel, from Val-des-Bois, France, in the last decade of the nineteenth century and the first of the twentieth century. Attention is given to the Christian corporation model and the bon patron culture that Menezes learned from Harmel. Menenez brought the model to Brazil, adapted it and recreated it in Camaragibe.

Keywords: Christian corporation; social Catholicism; associationism; labour history; transnational history.

Doutor em História Social pela Unicamp. Pesquisa desenvolvida com recurso do PNPD/CAPES, no CPDOC/FGV. Na Europa, foi viabilizada pelo Scholarship Programme for Young Professors do Coimbra Group e pelo KADOC/KU Leuven. E-mail: amaraldga@gmail.com. ORCID: http://orcid.org/0000-0002-3828-2280 


\section{Introdução}

Desde a última década do século XIX, organizações confessionais voltadas aos trabalhadores foram criadas em Camaragibe, nos arredores de Recife. Em um intervalo de uma década, os clubes e associações dos trabalhadores da Fábrica de Tecidos de Camaragibe expandiram suas atividades e passaram a integrar uma rede de organizações católicas na região. Patrocinadas por Carlos Alberto de Menezes e, posteriormente, por Pierre Collier, ambos diretores da Fábrica de Tecidos, as organizações surgidas na vila operária de Camaragibe deram origem, em 1902, à Federação Operária Cristã, influente não só em Recife, mas também em Alagoas, Ceará e Rio Grande do Norte. Menezes e Collier faziam uso da força política fornecida pela rede de associações que dirigiam e de sua missão de fé para se manterem articulados, tanto com os clérigos locais e outros movimentos religiosos, quanto com políticos com os quais negociavam meios de conquistar melhorias nas condições de vida e trabalho dos trabalhadores e, ainda, conseguir avanços na legislação social, naqueles tempos praticamente inexistente. Eles praticavam um tipo de gerenciamento do trabalho, inspirado nos ensinamentos sociais da lgreja, e criaram corporações, sindicatos, sociedades mutuais e cooperativas, além de escolas religiosas, nas vilas operárias do conglomerado industrial que participavam, a Companhia Industrial Pernambucana. O modelo de gerenciamento da fábrica e de relação com os trabalhadores escolhido por Menezes originou-se de transferências e interações transnacionais, especialmente com a França.

O modelo foi escolhido por Carlos Alberto de Menezes, após uma viagem à França, onde pessoalmente conheceu a experiência da fábrica de Val-des-Bois, propriedade de Léon Harmel. Empresário, militante e pensador católico, transformou sua usina em uma corporação cristã. A interação entre Menezes e Harmel foi decisiva para que o modelo de corporação cristã fosse adotado em Pernambuco. Como se deu a interação entre Menezes e Harmel? Por quais meios foi efetivada a recriação do modelo francês de corporação cristã para uma cidade brasileira? Quais foram as adaptações locais realizadas no Brasil? Este artigo objetiva analisar as interações e transferências transnacionais entre corporações operárias confessionais e o ativismo de leigos católicos, especialmente de empresários, neste caso, entre Brasil e França. Interessa especialmente entender as conexões de Pernambuco com o caso de Léon Harmel, em Val-des-Bois, na última década do século XIX e primeira do século XX, com atenção especial à cultura do bon patron, que Menezes aprendeu com Harmel, e sua adaptação à realidade brasileira. Propõe-se uma abordagem transnacional para a compreensão de como a história da manifestação do catolicismo nos mundos do trabalho, nesses dois países, esteve de certa maneira conectada. 
Tanto no campo da história da religião, quanto da história social do trabalho, a presença do catolicismo na organização de trabalhadores é sub-representada nas pesquisas acadêmicas, especialmente naquelas com recorte temporal anterior a 1935, quando a Igreja hierarquizou o controle do movimento por meio da Ação Católica Brasileira (ACB), incentivou o circulismo e a juventude operária. ${ }^{1}$ As diretrizes mais restritas impostas pela Igreja à sua militância leiga, a partir de 1935, aliadas às profundas mudanças na legislação trabalhista brasileira, criaram narrativas bastante focadas na ação hierárquica e institucional dos movimentos liderados pela lgreja. Se fato é consenso historiográfico que a ACB é um marco importante, os estudos centrados apenas em suas ações acabam ocultando importantes experiências anteriores de ativismo católico.

O caso em análise aqui parece ter sido uma das primeiras manifestações no Brasil do que na Europa é conhecido como sindicalismo cristão ou, pelo menos, da militância confessional nos mundos do trabalho. Ademais, trata-se de uma experiência em que o paternalismo patronal ocupava lugar importante, contudo, com claras implicações para a organização dos trabalhadores. Tal qual no caso europeu, em Pernambuco, esse associativismo aconteceu com o patrocínio de patrões que eram militantes católicos. Destacar esse caso pode fornecer uma melhor compreensão das relações entre religião e sociedade e, especificamente, da conformação da matriz cristã da organização dos trabalhadores em um país que a própria Igreja nomeava um "país católico"2.

\section{Carlos Alberto de Menezes e Camaragibe: catolicismo militante e associativismo confessional}

Em 1891, o industrial Pereira Carneiro, nascido na Argentina e radicado em Pernambuco, fundou, juntamente com vários sócios minoritários, a Companhia Industrial Pernambucana (CIPER) e, para dirigi-la, convidou o engenheiro Carlos Alberto de Menezes. A CIPER, inicialmente, conglomerou a Usina de Goiana, de propriedade de Pereira Carneiro, e uma nova indústria ainda a ser projetada, uma fábrica de tecidos nos arredores de Recife. A principal tarefa de Menezes era projetar e construir o que viria a ser, quatro anos mais tarde, a Fábrica de Tecidos de Camaragibe. Ao aceitar o cargo, que veio acompanhado de uma participação

1 AZZI, Riolando. O início da restauração católica no Brasil (1920-1930). Síntese, n.10, maio-ago. 1977; SOUZA, Jessie Jane Vieira de. Círculos Operários: a Igreja católica e o mundo do trabalho no Brasil. Rio de Janeiro: UFRJ, 2002. 320 p.

2 Bispos usaram recorrentemente a expressão desde a separação entre Igreja e Estado, em 1891. Um marco importante é a carta pastoral de Dom Leme, em 1916. 1a Carta Pastoral de Dom Sebastião Leme, Arcebispo de Olinda, 16/07/1916. 
acionária, Menezes convenceu os sócios a incluir um artigo sobre a condição dos operários nos estatutos da CIPER.

\begin{abstract}
Manter em todas as suas fábricas uma organização de trabalho fundada no espírito de associação e em que se tenha em vista melhorar a situação do operário, promovendo 0 seu aperfeiçoamento não só em aptidão técnica e profissional como em moralidade, auxiliando seu pessoal na criação e manutenção de escolas, hospitais, instituições de beneficência, auxílio mútuo, instrução, divertimento etc., e em quaisquer instituições em que o operário possa elevar-se moral e intelectualmente, e atender de modo regular e eficaz à educação de seus filhos. ${ }^{3}$
\end{abstract}

A insistência em incluir o dispositivo estatutário revelava o intento de Carlos Alberto Menezes de projetar uma companhia cujas fábricas seguissem princípios cristãos de organização do trabalho. Isso ficará claro no projeto executado de construção da Fábrica de Camaragibe e de sua vila operária, bem como do programa administrativo implementado por Menezes. Ademais, a experiência organizativa dos trabalhadores da fábrica se deu muito pela ação de Menezes, que fundou corporações cristãs e estimulou seus operários a se filiarem a elas. Antes, porém, uma observação se faz necessária: os estatutos da Companhia Industrial Pernambucana foram registrados em 23 de janeiro de 1891, quase quatro meses antes da publicação da encíclica Rerum Novarum, de 15 de maio. Isso demonstra como Menezes estava ciente e envolvido com todo o processo que antecedeu e conformou a doutrina social da Igreja, só oficializada pela carta papal de Leão XIII. Talvez seja exagero afirmar que Carlos Alberto de Menezes tenha sido vanguardista, mas certamente foi agente ativo da ação social católica, no momento de sua conformação como doutrina. A trajetória pessoal de Menezes oferece indícios importantes para se compreender sua atuação como militante católico e também como empresário. Nesse aspecto, o processo de elaboração do projeto da fábrica de Camaragibe revela-se um ponto crucial, pois foi neste momento que sua militância guinou de forma incisiva para a promoção do associativismo dos trabalhadores.

\title{
2. O catolicismo militante de Carlos Alberto de Menezes
}

Nascido no Rio de Janeiro, em 1855, e falecido em 1904, em Recife, Carlos Alberto de Menezes estudou no Colégio Pedro II e se tornou engenheiro pela Escola Politécnica Fluminense, em 1878, mesmo ano em que iniciou sua militância católica ao ingressar no movimento vicentino ${ }^{4}$. Casou-se com Maria Angélica Lacerda, filha

3 Estatutos da CIPER. AZEVEDO, Ferdinand. Ação social católica no Brasil: corporativismo e sindicalismo. São Paulo: Edições Loyola, 1986. p. 17.

4 Conferências de São Vicente de Paulo, criadas em Paris, França, em 1833 e, no Brasil, em 1873. 
do baiano Antônio de Lacerda, construtor do elevador Lacerda, em 1880, com quem teve nove filhos. ${ }^{5} \mathrm{Na}$ década de 1880 , já em Pernambuco, Menezes participou ativamente da formação de organizações católicas. Em 1888, participou da criação do Círculo Católico de Pernambuco, voltado à agremiação da mocidade sob os princípios morais cristãos, sobretudo aos estudantes da Faculdade de Direito. ${ }^{6} \mathrm{O}$ círculo durou até 1891, todavia, antes disso, em 1890, abrigou em sua sede o recém fundado Partido Católico de Pernambuco. Carlos Alberto de Menezes, em seu único envolvimento direto com a política partidária, malogrou ao tentar eleger-se Deputado Federal, em 1891, pelo Partido Católico. ${ }^{7}$ Como essa breve biografia demonstra, Menezes envolveu-se profundamente com o catolicismo desde a juventude. Foi durante a elaboração do projeto da Fábrica de Tecidos de Camaragibe, pela combinação da vida militante e industrial, que sua militância atingiu maturidade, especialmente a partir da interação com a experiência europeia.

Dividido entre a vida associativa, política e profissional, Carlos Alberto de Menezes partiu, em 1891, para uma longa viagem de trabalho que alimentaria suas ambições de militante e de industrial. Para o planejamento da fábrica de tecidos, Menezes foi enviado ao Rio de Janeiro e depois à Europa, para estudar modelos de plantas e comprar maquinário. Durante a estada na França, além de conhecer diversas tecelagens que serviriam de modelo para o projeto de Camaragibe, Carlos Alberto conheceu a experiência da fábrica de Léon Harmel, em Val-des-Bois. Menezes havia lido sobre Harmel e a Usina de Val-des-bois nos Boletins Vicentinos e decidiu aproveitar a oportunidade para fazer uma visita, a qual foi definidora e inspiradora para a organização social de sua unidade fabril.

Léon Harmel (1829-1915) foi um industrial francês que fez de sua fábrica de tecidos o laboratório para a formação de uma corporação cristã. ${ }^{8}$ O prédio central do complexo era a capela e o próprio Harmel vivia com sua família na vila operária. $\mathrm{Na}$ França, com intermédio de Harmel, Menezes fez contato com padre Léon Déhon (1843-1925), fundador da Congregação dos Sacerdotes do Sagrado Coração de Jesus, que tinha como missão a aproximação entre lgreja e povo por meio do trabalho social. O encontro proporcionou a primeira de várias ações de Menezes para trazer ao Brasil congregações religiosas. Menezes solicitou o envio de um padre da

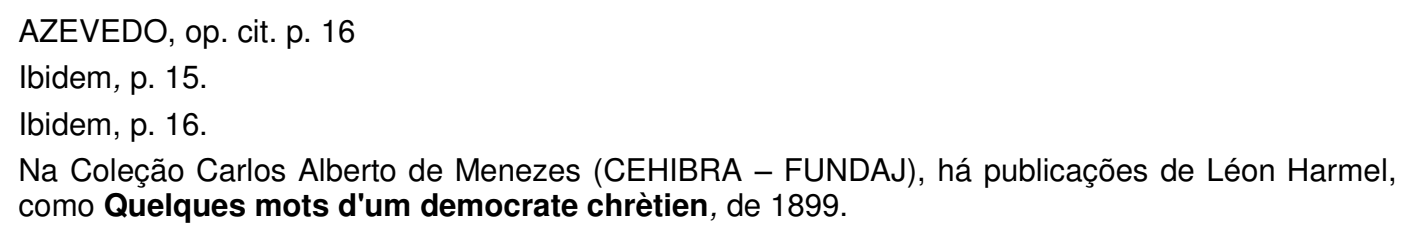


Congregação a Pernambuco, o que ocorreu com a chegada de Pe. SébastianFrançois Miquet, em 1893. ${ }^{9}$

Padre Déhon e Carlos Alberto de Menezes mantiveram-se em contato por muitos anos. Em 1901, Menezes fez outra visita a Padre Déhon na França, quando discutiram sobre a possibilidade de a Congregação enviar mais padres para Pernambuco, o que se efetivou ainda naquele ano. ${ }^{10}$ Naquela época, a Congregação já estava estabelecida em Recife e seus padres ensinavam na escola da vila operária de Camaragibe. Um deles era o capelão da vila operária. O próprio padre Léon Déhon visitou Camaragibe em 1906, o que pode ser conhecido em detalhes pelos registros de seu diário de viagens. ${ }^{11}$ Cabe destacar que todo o envolvimento de Menezes com as congregações religiosas tinha o objetivo de criar formas de educação religiosa para seus operários, ao exemplo da experiência da fábrica de Léon Harmel. Os dehonianos eram os capelães da vila operária de Val-des-Bois, utilizada na formação social dos padres da respectiva Congregação. A viagem aproximou Menezes de Déhon, mas sua relação com as congregações religiosas foi mais ampla. Posteriormente, em 1902, religiosas da Congregação das Filhas do Sagrado Coração de Jesus foram enviadas para ensinar as filhas dos operários nas escolas de Camaragibe. Em 1904, Menezes trouxe irmãos maristas para trabalharem como professores dos filhos dos operários da Fábrica de Tecidos de Camaragibe. ${ }^{12}$ O protagonismo de Menezes na vinda das congregações ao Brasil é notório, visto que o próprio Arcebispo de Olinda, Dom João Fernando, achava improvável que o projeto de Menezes se efetivasse. ${ }^{13}$

Além dos estudos para a construção da fábrica de tecidos, Menezes iniciou também um estudo sobre o associativismo confessional na França e trouxe consigo diversos impressos com estatutos de sindicatos, associações pias, mutuais e cooperativas francesas. Na Coleção Carlos Alberto de Menezes, guardada no arquivo da CEHIBRA-FUNDAJ ${ }^{14}$, há vários desses impressos que Menezes trouxe consigo da França ou, possivelmente, recebeu por correio. ${ }^{15}$ Ele recrutou, durante a

9 Léon Déhon. Notes Quotidiennes. - 6ème CAHIER, 26 juin 1892- 11 mars 1894. p. 18.

10 Léon Déhon. Notes Quotidiennes. - 17ème CAHIER - 1er juillet 1901- 24 août 1902. p. 7.

11 DÉHON, Léon. Mille lieues dans l'Amérique du Sud: Brésil, Uruguay, Argentine. Tournai, BE: Établissements Casterman, 1909.

12 AZEVEDO, op. cit. p. 18

13 MENEZES, Carlos Alberto. Memória sobre as obras de Camaragibe. [Recife: 19--]. Não publicado.

14 FUNDAÇÃO JOAQUIM NABUCO. Coordenação-Geral de Estudos da História Brasileira.

15 Entre os documentos: CERCLE CATHOLIQUE D'ETUDIANTS DE PARIS. Statuts, 1888 ; Séance Annuelle, 1890; Rerum Novarum, 1891, impressa em francês; Une usine chrétienne à Watten (nord), 1891 ; LIGUE DEMOCRATIQUE BELGE. Statuts, 1892; LE CONGRES OUVRIER REGIONAL DE REIMS, 1893; HARMEL, Léon. Quelques mots d'un democrate chrètien, 1899; Correspondência recebida por Carlos Alberto de Menezes e remetido por Chrétien Crick de Bruxelas, 
mesma viagem à Europa, o jovem engenheiro francês Pierre Collier para trabalhar na fábrica de Camaragibe. Posteriormente, Collier casou-se com a filha mais velha de Menezes, Maria Adélia. Embora não seja objeto desde texto, cabe destacar que Collier tornou-se o diretor da fábrica em 1904, quando Menezes adoeceu e morreu. Collier foi um continuador da obra empresarial e do ativismo católico de Menezes, pelo menos até a década de 1920. Seguindo as diretrizes de trabalho estabelecidas pelo sogro, Pierre Collier manteve contato com a Corporação Operária Cristã de Valdes-Bois, o que pode ser constatado por várias cartas publicadas nos Échos du Valdes-Bois, pelo menos até $1912 .{ }^{16}$ Isto mostra que a interação transnacional continuou por vários anos, enquanto o lado brasileiro estava modelando sua organização.

Após retornar ao Brasil, Carlos Alberto de Menezes iniciou a construção da Fábrica de Tecidos de Camaragibe, que já incluía em seu projeto original a vila operária, a escola e a igreja em seu entorno. Menezes vivia com sua família na vila operária de Camaragibe. Inaugurada em 1895, a fábrica entrou em funcionamento com 599 operários (277 homens, 197 mulheres e 60 meninos), seis dias de trabalho por semana, com jornada de 10 horas. ${ }^{17}$ Concomitantemente aos trabalhos de direção da Fábrica de Tecidos de Camaragibe, Menezes estimulou a criação de organizações sociais confessionais entre seus operários. Entre 1895 e 1900, foram fundadas a Sociedade Cooperativa de Consumo, a Associação das Filhas de Maria, o Clube Musical e o Clube Dramático. Em 1900, foi fundada a Sociedade de Mútuo Socorro dos Operários de Camaragibe. Todas as organizações foram reunidas, também em 1900, na Corporação Operária de Camaragibe, para a qual Menezes elaborou os estatutos. Durante essa elaboração, Menezes já indicava em suas anotações a dificuldade de adequar uma corporação operária à legislação brasileira da época, que não regulava a atividade dos sindicatos, algo que será detalhado na próxima seção. ${ }^{18} \mathrm{O}$ formato da Corporação Operária era semelhante ao modelo de corporação cristã elaborado por Léon Harmel. Cabe destacar que, em 1908, a Corporação Operária de Camaragibe tornou-se um sindicato profissional, em atenção ao Decreto-lei no 1.637, de 1907.

Durante sua estada no Brasil, Léon Déhon escreveu um artigo para o periódico La Chronique du Sud-Est, narrando suas primeiras observações sobre o cotidiano de

1900; CONGRES DES MUTUALITES SCOLAIRES, 1901; LE PEUPLE JOURNAL DEMOCRATIQUE CHRETIEN, 1901; LE CONGRES OUVRIER DE LILLE [19- ?].

16 As cartas publicadas nos Échos du Val-des-Bois tratavam de temas cotidianos, legislação trabalhista e a criação de associações católicas.

17 COMPANHIA INDUSTRIAL PERNAMBUCANA. Relatório. 1895; COMPANHIA INDUSTRIAL PERNAMBUCANA. Exposição industrial. Rio de Janeiro: Tipografia Mont'Alverne, 1895. p. 3-7.

18 Ata da primeira assembleia da Corporação Operária de Camaragibe, 1900. 
Camaragibe e sobre a corporação cristã. É interessante notar que ele detalhou alguns aspectos da vida social e também destacou o caráter misto da corporação.

Déhon destacou a rápida expansão do modelo de corporação cristã:

O que se faz ainda não é considerável, mas é bastante original. Difere-se das nossas obras da França e é curioso de se estudar.

... Carlos Alberto de Menezes, após a emancipação dos escravos em 1888, compreendeu que havia outra coisa a fazer para elevar os operários, para dar-Ihes o sentimento de sua dignidade pessoal e a consciência do dever social.

Ele havia lido nos Boletins de São Vicente de Paulo artigos sobre as obras de Val-des-Bois e resolveu se tornar um segundo León Harmel.

Ele se entusiasmou com Val. Quis um capelão para ajudá-lo. Ele me visitou, solicitou-me e eu o dei. [...]

A Fábrica de Camaragibe, o Val-des-Bois do Brasil, tem seu capelão, suas escolas de Irmãs e Irmãos e diversas instituições econômicas. ... Outras fábricas imitaram Camaragibe, notadamente a usina de açúcar de Goyana, a fiação de Paulista, a usina do senhor Van Desmet, na Bahia.

Os patrões formaram com os operários uma Corporação, um sindicato misto legal e regular, não para a administração da usina em si, mas para a administração dos serviços anexos: culto, escolas, socorro mutual, cooperativa, recreações, etc.

Os operários... São de raça portuguesa, um pouco misturada com o sangre negro e indígena.

As vilas operárias e suas fábricas cristãs contrastam os vilarejos do país. ...As ruas são limpas, alinhadas e com belas árvores tropicais plantadas. São equipadas com fontes..$^{19}$

A narrativa detalhada de padre Déhon é bastante rica e desvela aspectos significativos da vida em Camaragibe, na primeira década do século. Além de enfatizar o pioneirismo e o perfil militante de Carlos Alberto de Menezes, o destaque dado ao sindicato misto e legal é controversa. O Decreto-lei 1.637, que regulamentou a atividade sindical pela primeira vez no Brasil, é de janeiro 1907. Em 1906, contudo, já havia sido votado, aprovado e esperava publicação. Déhon se adiantou em falar em "sindicato misto legal e regular", provavelmente porque soube do envolvimento de Menezes na elaboração do decreto-lei e, ainda, a Corporação Operária de Camaragibe possivelmente já estava adiantada nos preparativos dos novos estatutos para adequação à lei. A presença negra entre os operários é também importante de ser destacada; não obstante a dificuldade de encontrar essa informação em fichas de operários, relatórios de fábrica e outras fontes, é possível que parcela dos trabalhadores seja formada por negros. Além de fazer referência à abolição da escravidão, o padre Léon Déhon destaca em seu diário a miscigenação entre portugueses, negros e indígenas. Cabe destacar que, aos olhos de um estrangeiro,

19 DÉHON, Léon. Une forme de la corporation chrétienne au Brésil. La chronique du Sud-Est, n. 11, p. 327-328, nov. 1906. 
a presença indígena e negra salta aos olhos e poderia até mesmo tratar-se de uma descrição caricata, contudo, pode-se tomá-la como indício da conformação da classe trabalhadora de Camaragibe ${ }^{20}$. Por último, mesmo que a narrativa de Déhon seja exagerada para valorizar a gestão religiosa da fábrica, da corporação e da vila operária, é relevante destacar o contraste apontado entre Camaragibe e outras regiões do país. Déhon vinha de viagem longa e, antes de chegar a Camaragibe, já havia passado pela Argentina, Uruguai, estados do sul do Brasil, Rio de Janeiro e Bahia. $^{21}$ O padre francês, líder da Congregação do Sagrado Coração, tinha elementos para a comparação.

No que tange à singularidade da corporação, entretanto, é importante notar que esse tipo de organização não tinha precedentes no Brasil. Apesar da existência anterior de organizações mutuais e corporações de artesãos no Brasil e mesmo em Recife $^{22}$, este tipo de organização que conglomerava várias atividades e era, adicionalmente, confessional, era completamente nova. O modelo de indústria com vila operária e ação paternalista da administração já se disseminava na virada para o século XX, no Brasil. ${ }^{23}$ Era, decerto, uma característica dessa época. O fator confessional é a novidade nesse caso. A questão se torna mais complexa quando se considera a ação paternalista acrescida do fator religioso. O apelo à moral religiosa e ao aspecto espiritual da vida dos trabalhadores, conjugado com a ação patronal no estímulo e patrocínio às atividades cooperativas, de auxílio mútuo, de lazer e mesmo sindicais, pode ter criado uma ligação muito forte entre trabalhadores e patrões. Por outro lado, não se pode negar que o espaço de convívio em associações e os benefícios que os trabalhadores de Camaragibe tinham (escolas, clubes dançantes, mutualidades, etc.) devem ser considerados, tanto como espaços de conscientização política sobre o trabalho, quanto como elementos que criam uma hierarquização da qualidade de trabalho, na medida em que a maioria dos trabalhadores daquela época não tinha acesso a tais serviços. No cerne dessa discussão, está a incompatibilidade

20 Sobre a diversidade da classe trabalhadora brasileira: ROEDIGER, David. E se o trabalho não fosse branco e masculino? In: FORTES, Alexandre et al. Cruzando fronteiras: novos olhares sobre a história do trabalho. São Paulo: Perseu Abramo, 2013.

21 DÉHON, Léon. Mille lieues dans l'Amérique du Sud: Brésil, Uruguay, Argentine. Tournai, BE: Etablissements Casterman, 1909.

22 MAC CORD, Marcelo. Artífices da cidadania: mutualismo, educação e trabalho no Recife oitocentista. Campinas: Editora da Unicamp, 2012. 438 p.

23 NEGRO, Antonio Luigi. Paternalismo, populismo e história social. Cadernos AEL, v.11, n. 20/21, 2004; COSTA, Mariana Barbosa Carvalho da. Entre o lazer e a luta: o associativismo recreativo entre os trabalhadores fabris do Jardim Botânico (1895-1917). 2014. Dissertação (Mestrado em História) - Pontifícia Universidade Católica do Rio de Janeiro, Rio de Janeiro, 2014; PIRES, Isabelle. Entre teares e lutas: relações de gênero e questões etárias nas principais fábricas de tecidos do distrito federal (1891-1932). 2018. Dissertação (Mestrado em História) - Fundação Getúlio Vargas, Rio de Janeiro, 2018; STEIN, Stanley J. Origens e evolução da indústria têxtil no Brasil 18501950. Rio de Janeiro: Campus, 1979. 
entre resistência de trabalhadores ${ }^{24}$ e paternalismo dominador ${ }^{25}$, que ocupa há décadas os debates no campo da história social do trabalho.

Carlos Alberto de Menezes, entretanto, não esperou muito antes de envidar esforços em uma iniciativa mais ambiciosa. Durante o Congresso Católico de Pernambuco, realizado em 1902, as discussões sobre organizações cristãs de trabalhadores baseavam-se na experiência recente de Camaragibe, mas já indicavam a necessidade de uma ação mais ampla. Para enfrentar o medo da luta de classes e o fortalecimento do ramo cristão da organização dos trabalhadores, Menezes propôs a criação de uma organização maior que congregasse outras associações confessionais e que também estimulasse a criação de novas corporações católicas.

\section{Federação Operária Cristã}

Carlos Alberto de Menezes destacou-se também por sua propaganda do catolicismo social e ações como patrão, que lhe fizeram ganhar destaque entre as lideranças católicas no meio operário. ${ }^{26}$ Menezes foi ainda fundador da Federação Operária Cristã, em 1902, organização que tinha como associadas, incialmente, a Corporação Operária de Camaragibe, a União Beneficente dos Empregados da Companhia Ferro Carril, a Associação dos Filhos de São José da Fábrica de Tecidos Paulista ${ }^{27}$, além de trabalhadores da Fábrica de São José do Gravatá e da Usina de Goiana. ${ }^{28}$ Apenas a Corporação Operária de Camaragibe e a Usina de Goiana estavam diretamente ligadas à CIPER, dirigida por Menezes. Toda essa ramificação demonstra que a organização católica estava se espalhando pela região, desde seu início na década anterior, em Camaragibe.

24 Estudos sobre a escravidão inauguraram o debate sobre resistência dos trabalhadores, livres ou não, e as interpretações avançaram ao período republicano. CHALHOUB, Sidney. Visões da liberdade. São Paulo: Companhia das Letras, 2011; CHALHOUB, S.; SILVA, Fernando T. Sujeitos no imaginário acadêmico: escravos e trabalhadores na historiografia brasileira desde os anos 1980. Cadernos AEL, Campinas, n.26, 2009; LARA, Silvia H. Escravidão, cidadania e história do trabalho no Brasil. Projeto História Revista do Programa de Pós-graduados de História, São Paulo, n. 16, 1998.

25 Cito duas visões desse paternalismo: STEIN, op. cit.; LOPES, José S. L. A tecelagem dos conflitos de classe na cidade das chaminés. São Paulo: Marco Zero, 1988.

26 Sobre Menezes, há pelo menos dois textos hagiográficos: MENEZES; AZEVEDO, op. cit. e COLLIER, Eduardo. Carlos Alberto de Menezes. Recife: Digital Graph 1996. Para uma análise acadêmica: AGUIAR, Sylvana Maria Brandão de; LIMA, Lúcio Renato Mota. A fábrica de tecidos de Camaragibe e sua organização cristã do trabalho (1891-1908). REVTEO - Revista de Teologia e Ciências da Religião da UNICAP/PE, v. 1, n. 1, p.160-195, dez 2012.

27 LOPES, op. cit.

28 BRITO, Luiz de Correa. O movimento social católico em Pernambuco. In: CONGRESSO CATÓLICO BRASILEIRO, 2., 1908, São Sebastião do Rio de Janeiro. Atas e documentos. Rio de Janeiro: Off. d'O universo, 1910. p. 330. 
Menezes presidiu o I Congresso Católico, em Salvador, em 1900, quando palestrou sobre a questão operária. Participou também dos congressos regionais pernambucanos. Em Salvador, em tom conservador, afirmou que a questão operária era decorrência da herança da escravidão e dos hábitos incivilizados dos brasileiros. Discursou contra o concubinato e a desvalorização da família. Menezes dizia que era preciso conscientizar os patrões da grande indústria sobre a necessidade de disciplinar e moralizar as classes populares pela religião. Para tanto, era preciso fazer a propaganda católica e arregimentar um exército "adestrado e munido do armamento superior da fé" 29 . Menezes era, em certa medida, um personagem ambíguo. Apesar de assumir o discurso conservador, típico da militância católica, ele demonstrou capacidade de construir uma estrutura de ação social católica sólida, que embasou as organizações criadas em Camaragibe.

A influência das ações de Menezes avançou as fronteiras do estado de Pernambuco e conseguiu adeptos nos estados vizinhos. A Federação Operária Cristã tinha, nos primeiros anos do século XX, cerca de 6 mil operários sob sua influência em Pernambuco, Alagoas, Bahia, Rio Grande do Norte e Sergipe. ${ }^{30}$ Houve, ainda, tanto em Pernambuco quanto em Alagoas, intenso debate na imprensa operária socialista, que confrontava a cultura militante católica, acusando suas organizações de não defenderem os trabalhadores. Em 1906, o periódico Aurora Social, do Centro Protetor dos Operários de Recife, por exemplo, criticou o sindicalismo cristão e declarava abertamente que o Centro era adversário da Federação Operária Cristã. ${ }^{31}$ Os estudos sobre as organizações operárias recifenses destacam a forte presença socialista entre a última década do século XIX e as primeiras do século XX e parece ter havido em Recife uma disputa real por espaço no meio operário. ${ }^{32}$ Esta disputa se revela contrastante com outras experiências de associativismo confessional de trabalhadores na Primeira República (1889-1930), sobretudo com o caso de Belo Horizonte, onde a presença de correntes socialistas ou anarquistas durante o auge do sindicalismo católico foi insignificante. ${ }^{33}$

A Federação Operária Cristã contava com um Grupo de Estudos Sociais, criado em 1903, do qual Menezes participava ativamente como palestrante e propondo

29 MENEZES; AZEVEDO, op. cit., p. 48.

30 MACIEL, Osvaldo Batista Acioly. Trabalhadores, identidade de classe e socialismo: os gráficos de Maceió (1895 - 1905). Maceió: Editora da UFAL, 2009. p. 173.

31 Ver, por exemplo, Aurora Social, Anno V, n. 1 e 8, de 1906. APEJE.

32 REZENDE, Antônio Paulo de Moraes. A classe operária em Pernambuco: cooptação e resistência. 1890/1922. 1981. 207f. Dissertação (Mestrado em História) - Instituto de Filosofia e Ciências Humanas, Universidade Estadual de Campinas, Campinas, 1981.

33 AMARAL, Deivison. Catolicismo e trabalho: a cultura militante dos trabalhadores de Belo Horizonte (1909-1941). Curitiba: Editora Appris, 2018. 
temáticas de estudo. ${ }^{34}$ Menezes organizou no interior do Grupo um estudo estatístico sobre a situação dos trabalhadores de vários ofícios. Criou-se um manual com diretrizes para as equipes que se ocupariam da pesquisa. O manual incluía indicadores, tais como jornada de trabalho, descanso semanal, salário, taxa de ocupação, trabalho infantil, trabalho feminino, formas de aprendizagem do ofício, frequência de acidentes de trabalho, doenças reincidentes em operários, higiene dos locais de trabalho, punição por trabalhos mal executados, existência de associação beneficente, entre outros ${ }^{35}$. Esse estudo estatístico não será analisado de forma pormenorizada aqui, contudo, cabe citar algumas das categorias incluídas: condutores, estivadores, relojoeiros, barriqueiros, marceneiros, carpinas, carpinteiros, trabalhadores de fundição geral, foguistas, calafates, armeiros, carvoeiros, têxteis, cigarreiros, tipógrafos, entre outras. ${ }^{36}$ Além disso, alguns levantamentos são nomeados não por ofício, mas pelo nome da empresa em que os operários eram empregados. Cabe ressaltar que esse estudo é um exemplo da visão abrangente que a Federação tinha sobre os mundos do trabalho, na medida em que buscava entender as condições laborais para propor soluções.

Foi do interior do Grupo de Estudos Sociais, por iniciativa de Menezes, que surgiu o anteprojeto da primeira lei sindical do Brasil. A preocupação de Menezes com a falta de legislação específica para sindicatos no Brasil era antiga. ${ }^{37} \mathrm{Em} 1903$, ele se correspondeu com o deputado federal Inácio Tosta e enviou-Ihe seus estudos e o anteprojeto de lei que, em 1907, seria aprovada como a Lei 1.637, regulamentando a formação de sindicatos e cooperativas no Brasil. ${ }^{38} \mathrm{Em}$ seu discurso durante a sessão de aprovação da lei na Câmara dos Deputados, Inácio Tosta manifestou sua gratidão a Menezes, à época já falecido, e o proclamou o "Léon Harmel brasileiro"39. Este tributo pós-morte, ligando discursivamente Menezes e Harmel, é também indício do quanto suas trajetórias eram conectadas. Não obstante Harmel não ser tão famoso quanto outros católicos militantes franceses, como Albert de Mun e La Tour du Pin, a referência a ele em uma sessão legislativa brasileira é

34 FEDERAÇÃO OPERÁRIA CRISTÃ. Estatutos. Preâmbulo de Carlos Alberto de Menezes. Recife: 1902. (Coleção Pierre Collier, FUNDAJ).

35 FEDERAÇÃO OPERÁRIA CRISTÃ. Pontos a considerar no estudo estatístico. Recife: FUNDAJ, [19--] (Coleção Pierre Collier),

36 FEDERAÇÃO OPERÁRIA CRISTÃ. Estudo estatístico sobre as condições de trabalho em várias categorias. Recife: FUNDAJ, [19--]. (Coleção Pierre Collier).

37 Há anotações feitas à mão nas margens da impressão da ata de fundação da Corporação Operária de Camaragibe, na Coleção Carlos Alberto de Menezes, CEHIBRA-FUNDAJ. Ata da primeira assembleia da Corporação Operária de Camaragibe. 1900.

38 TOSTA, Joaquim Inácio. Projeto sobre sindicatos profissionais e cooperativas. Recife: Typ. Silva e Ribeiro,

39 TOSTA, Joaquim Ignácio. Discurso Diário do Congresso Nacional, Ano 17, n. 46, 29 jun. 1905. p. 397. 
significativa dessa conexão. Cabe notar que Harmel também esteve envolvido em debates públicos sobre a legislação trabalhista francesa, nas décadas finais do século XIX. Em 1880, ele criticou abertamente Albert de Mun, então deputado, por ter retirado projeto sobre a regulação do trabalho que eles haviam discutido conjuntamente e que propunha, entre outras coisas, a abolição do trabalho noturno das mulheres, o descanso dominical e a liberdade de associação. ${ }^{40}$

Embora a trajetória de Carlos Alberto de Menezes na ação social católica date da década de 1870, a viagem à França e o contato com Léon Harmel, em 1891, foi um momento decisivo para os contornos de sua militância e da organização de sua fábrica nos anos seguintes. Ao conhecer a experiência da fábrica de Harmel, Menezes parece ter voltado ao Brasil decidido a fazer de Camaragibe um espelho de Val-des-Bois. A próxima seção se ocupará da experiência francesa a fim de contextualizar e entender o princípio da corporação cristã e a ação patronal e, ademais, destacar características do modelo que Menezes trouxe ao Brasil. Isso possibilitará melhor entender as conexões entre as duas experiências.

\section{Léon Harmel e Val-des-Bois: militância patronal e corporação cristã}

Léon Harmel representa a terceira geração de uma família de industriais franceses que, desde fins do século XVIII, empreendeu diversas iniciativas no norte da França, sul da Bélgica e sul dos Países Baixos. Seu avô, Jacques Harmel, já possuía fábricas durante os acontecimentos revolucionários de 1789. Em 1793, a casa da família foi destruída pelo exército revolucionário e forçou um recomeço no sul da Bélgica. ${ }^{41}$ Léon Harmel assumiu o comando das indústrias quando seu pai, Jacques-Joseph, adoeceu, em 1854, e a família já estava finalmente instalada em Val-des-Bois, departamento de Marne, ao norte da França.

Apesar das indústrias da família Harmel serem prósperas economicamente, Léon ficou conhecido por sua militância católica. É considerado membro de menor destaque da tríade de militantes católicos que surgiu após a Guerra FrancoPrussiana (1870-71) e a Comuna, juntamente com La Tour du Pin (1834-1924) e Albert de Mun (1841-1914). Albert de Mun, foi político, defensor da monarquia e ativista do catolicismo. É considerado um dos expoentes do pensamento conservador francês e conhecido como um dos teóricos do corporativismo católico

40 TRIMOUILLE, Pierre. Léon Harmel et l'usine chrétienne du Val-des-Bois (1840-1914): Fécondité d'une expérience sociale. Centre d'histoire du Catholicisme de Lyon, Lyon, n.15, 1974. p. 68.

41 Ibidem, p. 13 
na França. Foi fundador da CEuvre des cercles catholiques d'ouvriers, conhecida como Círculos Operários, fundada em 1871, como reação conservadora à Comuna de Paris. François-René de La Tour du Pin Chambly foi militar e ativista católico. Logo após a Comuna, Harmel conheceu Albert de Mun e se juntou aos Círculos Operários, onde já militava La Tour du Pin. Como a república parecia ser uma realidade incontornável, não havia mais espaço para a política contrarrevolucionária e os três pensadores e ativistas católicos dedicaram-se, então, a criar formas de fortalecer a fé e a moral cristã no novo contexto político. Léon Harmel deixa clara sua posição na matéria em Quelques mots d'un démocrate Chrétien, de 1899, onde argumenta que, no contexto republicano, os cristãos deveriam agir para influenciar as massas, harmonizar a sociedade e evitar o avanço da influência socialista. O referido livro de Harmel foi encontrado no acervo da Coleção Carlos Alberto de Menezes. ${ }^{42}$

Albert De Mun, François René de La Tour du Pin e Léon Harmel representam, na verdade, um segundo momento do catolicismo social europeu. Desde o início do século XIX, houve um movimento associativo católico que se desenvolveu na Europa, sobretudo na Alemanha, Bélgica, França e Países Baixos. ${ }^{43}$ Havia uma matriz europeia de um catolicismo social (também chamado socialismo cristão) até meados do século XIX. Essa matriz se enfraqueceu e deu lugar ao conservadorismo antirrepublicanista. ${ }^{44}$ Movimentos cristãos de viés democráticos participaram ativamente dos movimentos revolucionários de 1848-49, em Paris. Nada obstante, em reação ao socialismo, o "catolicismo cresceu mais abertamente antirrepublicano e reacionário"45 durante o Segundo Império Francês (1852-70), sem, contudo, significar que sua matriz mais progressista e republicana desaparecesse completamente. ${ }^{46}$ Essa matriz mais progressista foi evocada, já no século XX, como pedra angular da social democracia cristã. ${ }^{47}$

42 Sob guarda do CEHIBRA-FUNDAJ.

43 MAYER, Jan De. The formation of a christian worker's culture in pillarized societies: Belgium, Germany and the Netherlands, c. 1850-1950. In: VOSS, Lex Heerma van; PASTURE, Patrick; MAEYER, Jan De (ed.). Between cross and class: comparative histories of Christian labour in Europe 1840-2000. Amsterdam: Peter Lang, 2005. p. 81-102.

44 MISNER, Paul. Catholic Labour Movements in Europe: Social Thought and Action, 1914-1965. Washington: Catholic University of America Press, 2015. p. 6.

45 Ibidem, p. 7.

46 Um destacado representante desta matriz progressista foi o bispo alemão de Mainz, Wilhelm Emmanuel von Ketteler que, em 1864, publicou A questão operária e o cristianismo.

47 Há autores que indicam a década de 1890 como ponto de partida para a social democracia francesa que, após a Segunda Guerra Mundial (1939-1945), ganhou proeminência política por meio do Mouvement Republicain Populaire (MPR). A social democracia tem fortes raízes nas ideias da democracia cristã. De Mun, La Tour du Pin e Harmel são frequentemente evocados como figuras importantes nesse processo. NORD, Philip G. Three views of christian democracy in fin de siècle France. Journal of Contemporary History, v. 19, n. 4, p. 713-727, Oct. 1984. Reassessments of Fascism. 
Na esteira dessas duas possibilidades de ação social católica, De Mun, La Tour du Pin e Harmel passaram a atuar conjuntamente nos Círculos Operários. A ação proposta nos Círculos era essencialmente paternalista e concentrou-se na conscientização dos industriais, impelidos a praticar ações sociais e caritativas, além de garantir que seus operários tivessem trabalho e vidas dignas. A ação social dos patrões vinculados ao catolicismo - por exemplo, Léon Harmel e Carlos Alberto de Menezes - é evocada atualmente como a origem da chamada "responsabilidade social das empresas". ${ }^{48}$ Essa visão de responsabilidade social é tributária da cultura do bon patron catholique, bastante forte na Bélgica e na França, para a qual Léon Harmel teve relevante papel em sua concepção. Cabe destacar que, dentre os três expoentes do catolicismo francês, Harmel desenvolveu um pensamento mais progressista e vinculado ao catolicismo social.

Harmel, mesmo trabalhando ao lado de Albert de Mun na L'oeuvre des cercles, resolveu dar uma guinada em sua compreensão da militância operária católica e da própria democracia cristã. ${ }^{49} \mathrm{~A}$ partir da última década do século XIX, passou a defender mais enfaticamente um tipo de sindicalismo livre no qual os próprios trabalhadores fossem os protagonistas. Renegava, então, o paternalismo característico de seus correligionários conservadores. Essa noção de um sindicalismo católico com autonomia dos trabalhadores, contudo, já vinha sendo amadurecida há mais tempo.

Em 1873, durante um congresso da L'Union des Oeuvres, em Nantes, Harmel disse que, no trato com os operários, os patrões deveriam saber distinguir o que "fariam eles mesmos do que deveria ser feito pelos outros" ${ }^{50}$. Durante o Congresso Operário Cristão de Reims, em 1893, Léon Harmel defendeu e ajudou a formar os Cercles Chrétiens d'Études Sociales (Círculos Cristãos de Estudos Sociais), que deveriam elaborar estudos e ser um espaço de formação dos trabalhadores sobre os princípios cristãos. ${ }^{51}$ Harmel costumava proferir palestras, seguidas de sessões com perguntas e respostas para trabalhadores. O objetivo manifesto dessas reuniões era oferecer um tipo de educação cristã em questões relacionadas ao mundo do trabalho. Nos últimos anos do século XIX, o Círculo Cristão de Estudos Sociais passou a discutir questões políticas e a eleição de representantes dos trabalhadores para cargos legislativos que fossem mais alinhados com a ideia de democracia cristã.

48 HEYRMAN, Peter. Belgian catholic entrepreneurs' organizations, 1880 to 1940: A dialogue on social responsibility. Journal of Business History, 56. Jahrg., H. 2, p. 163-186, 2011.

49 Há escritos de Léon Harmel sobre democracia cristã no acervo de Carlos Alberto de Menezes.

50 HARMEL, L. L'organisation chrétienne de l'usine, apud. TRIMOUILLE, Pierre, op. cit., p. 80.

51 TRIMOUILLE, op. cit., p. 84-85. 
Léon Harmel iniciou em sua fábrica, ainda na década de 1860, o modelo de "corporação cristã" que, posteriormente, serviria de modelo para a gestão da Fábrica de Tecidos de Camaragibe, em Pernambuco. Sua intenção inicial parecia ser guiada pela visão paternalista convencional para "salvar os operários cristianizando-os e moralizando-os" ${ }^{\prime 2}$. Anos mais tarde, em 1884, associado a outros empresários locais, criou a Association des Patrons Catholiques du Nord de la France, que rapidamente transformou-se numa rede de 177 companhias. Almejava o convencimento dos patrões e gerentes sobre a importância da adoção de um modelo de gestão cristã em suas indústrias. Sua estratégia inicial foi a criação de associações religiosas para os operários que, em seguida, seriam transformadas em associações profissionais cristãs.

A fábrica de Harmel seguia a organização típica de uma company town. Nos arredores de Val-des-Bois, cidade próxima a Reims, no norte da França, a família Harmel construiu a fábrica de tecidos cercada por uma vila operária, onde viviam todos os empregados, patrões e familiares. Na vida operária, havia uma igreja e uma escola para os filhos dos operários. Os operários participavam da gerência da fábrica por meio de comissões nomeadas Conselhos de Usina. ${ }^{53}$ Desde 1842, quando a fábrica era ainda dirigida por seu pai, Jacques-Joseph, os operários contavam com uma caixa beneficente. Léon Harmel aprofundou o conceito, ampliou os serviços da caixa beneficente, além de criar outras associações, voltadas para o lazer, formação cristã e educação dos operários. ${ }^{54} \mathrm{Na}$ medida em que Harmel desenvolvia seu conceito de ação social católica, a fábrica foi laboratório de suas experiências de gestão do associativismo dos operários, que mais tarde ele nomearia "corporação cristã" 55 .

A Comuna de Paris assustou os conservadores franceses que, na busca por formas de evitar que o socialismo e as ideias libertárias ganhassem terreno, voltamse à experiência de Harmel e veem nela um "laboratório social" bastante útil. ${ }^{56} \mathrm{~A}$ influência recíproca de Albert de Mun, La Tour du Pin e Harmel criou um conceito de corporação renovado. Na verdade, Harmel passou a adotar o nome de "corporação cristã" ao conjunto de organizações criadas para os trabalhadores de suas usinas. A diferença mais significativa de visão entre Harmel e seus dois colegas de tríade é, sem dúvida, a questão da autonomia e do paternalismo. Esse tema fez com que Harmel e De Mun rompessem relações em 1893. A militância de Léon Harmel foi

\footnotetext{
2 Ibidem, p. 9.

3 Ibidem, p. 85.

54 Ibidem, p. 16.

55 HARMEL, Léon. Manuel d'une corporation chrétienne par Léon Harmel. Paris, 1877.

56 lbidem.
} 
uma ação católica avant-la-lettre e, certamente, ajudou a conformar a doutrina que o Papa Leão XVIII publicou em $1891 .{ }^{57}$

Léon Harmel fez de suas indústrias um laboratório social único. O Manuel d'une corporation chrétienne, publicado por Harmel em 1877, reuniu suas primeiras ideias sobre a relação entre patrões e empregados. Já nesse manual, Harmel condenava a forma de paternalismo comumente empregado pelos patrões cristãos de sua época e afirmou que "as associações católicas, baseadas na liberdade, só se desenvolverão fecundamente pela independência cristã". ${ }^{58}$ Posteriormente, Harmel continuou a oferecer uma espécie de patronnage mais autônoma aos seus operários e, principalmente, buscou influenciar os outros patrões no mesmo sentido. Contudo, foi só em 1903 que ele deu o passo mais significativo ao encerrar sua participação nas atividades das corporações cristãs em suas empresas, deixando os operários livres para deliberem sem a presença do patrão. ${ }^{59}$

É justamente na década de 1890, já sob a vigência da doutrina social da Igreja oficializada na Rerum Novarum, quando Harmel preocupava-se mais incisivamente em buscar formas de garantir a autonomia dos operários e de suas organizações cristãs, que Menezes vai conhecer a experiência das corporações e da fábrica em Val-des-Bois. É nesse momento que as histórias de Val-des-Bois e Camaragibe se entrecruzam.

\section{O modelo de corporação cristã: de Val-des-Bois a Camaragibe.}

Refletir sobre duas experiências de associativismo católico nos mundos do trabalho é tarefa árdua. Os desafios que se impõem às pesquisas que se propõem a fazer históricas cruzadas, conectadas ou comparadas são muitos. Em contrapartida, tais análises oferecem algumas perspectivas relevantes que forçam olhar o objeto de pesquisa com outra perspectiva. A investigação das interações e transferências transnacionais neste caso é complexa, sobretudo quando se destaca o protagonismo dos patrões no incentivo ao associativismo dos trabalhadores. Não foi proposto, contudo, um estudo filiado ao campo historiográfico específico da história comparada, inaugurado com intenção universalizante por Marc Bloch ainda na

57 Harmel tinha relações próximas com Leão XIII. Em 1887, 1889 e 1890, liderou a peregrinação de operários e industriais franceses à Roma. A última delas contou com cerca de 10 mil operários.

58 HARMEL, op. cit.

59 ASSEMBLEE GENERALE DU SYNDICAT DU VAL-DES-BOIS. Échos du Val-des-Bois. Reims: 1906. p. 106. (1ère année) 
década de $1920^{60}$, mas apenas utilizar suas funções metodológicas para atingir os objetivos propostos.

São conhecidos os esforços em escrever uma história global do trabalho, sem intenção universalizante, mas com análises em escala global. ${ }^{61} \mathrm{O}$ esforço recente em se fazer abordagens transnacionais sobre a história do trabalho e dos trabalhadores é ainda mais evidente, sobretudo nos estudos sobre as conexões atlânticas, englobando experiências de migração e diáspora e, ainda, processos históricos conectados, com circulação de pessoas e ideias. ${ }^{62}$ No campo dos estudos da religião, especialmente no ramo católico, a expansão do catolicismo por todo o ocidente força historiadores a empreenderem estudos transnacionais para entender diferenças e similaridades na conformação das ações da Igreja e de leigos. ${ }^{63}$ Esses tipos de análise histórica fazem uso copioso dos métodos comparativos. A história transnacional, portanto, tem ocupado historiadores que refletem sobre a metodologia da história e tem igualmente ganhado destaque na produção historiográfica que se propõe, em geral, a conhecer processos históricos conectados direta e indiretamente, em diferentes regiões do mundo. ${ }^{64}$

As experiências da militância católica de leigos junto aos trabalhadores em fins do século XIX, em Val-des-Bois e em Camaragibe, apresentam uma conexão transnacional cheia de elementos, com interações e transferências diretas e indiretas entre Léon Harmel e Carlos Alberto de Menezes.

A primeira constatação mais óbvia refere-se à influência exercida pela experiência de Léon Harmel na ação desenvolvida por Carlos Alberto de Menezes. Menezes, ao conhecer Harmel e sua experiência, quis construir uma indústria e moldar uma estrutura de ação social para seus operários como a de Val-des-Bois. Tal qual a congênere francesa, ergueu a Fábrica de Tecidos de Camaragibe rodeada

$60 \mathrm{BLOCH}$, Marc. Pour une histoire comparée des sociétés européenes. Révue de Synthèse Historique, n. 6, p. 15-50, 1928.

61 São vários os estudos, mas os esforços do International Institute of Social History merecem destaque. LINDEN, Marcel van der. Trabalhadores do mundo: ensaios para uma história global do trabalho. Campinas, SP: Editora da UNICAMP, 2013.

62 SCOTT, Rebecca J; HÉBRARD, Jean. Provas de liberdade: uma odisseia atlântica na era da emancipação. Campinas: Editora da Unicamp, 2014.; LINEBAUGH, Peter; REDIKER, Marcus. A hidra de muitas cabeças: marinheiros, escravos, plebeus e a história oculta do Atlântico revolucionário. São Paulo: Cia. das Letras, 2008.

63 VOSS; PASTURE, MAEYER, op. cit.; PASTURE, Patrick. Histoire du syndicalisme chrétien international. Paris: L'Harmattan, 1999; ANDES, Stephen J. C., YOUNG, Julia G. (ed.). Local church, global church: Catholic activism in Latin America from Rerum Novarum to Vatican II. Washington: Catholic University of America Press, 2016.

64 KOCKA, Jürgen; HAUPT, Heinz-Gerhard. Comparison and beyond. In: KOCKA, Jürgen; HAUPT, Heinz-Gerhard. (ed.). Comparative and transnational history. New York / Oxford: Berghahn, 2011; FREDRICKSON, George M. From exceptionalism to variability: Recent developments in CrossNational Comparative History. The Journal of American History, v. 82, n.2, p. 587-604, sep. 1995. Sobre o movimento operário cristão na Europa, ver PASTURE, op. cit., 1999. 
por uma vila operária, uma Igreja, escolas e outros espaços de convivência. A fábrica de Camaragibe foi inaugurada em 1895, mesmo ano em que Menezes começou a lidar com o associativismo dos trabalhadores. Criou também organizações cooperativas, mutuais e recreativas, que foram posteriormente coligadas à Corporação Operária de Camaragibe. A estrutura organizativa da Corporação era similar ao modelo de corporação cristã desenvolvido por Léon Harmel. A comparação dos estatutos das duas organizações deixa clara essa similaridade. Em resumo, ambas as organizações tinham por objetivo principal reunir patrões e trabalhadores e suas respectivas famílias. Ademais, ambos os estatutos indicavam a intenção de buscar sempre benefícios espirituais, morais e materiais para os associados. As corporações tinham organizações similares agregadas, por exemplo, sociedades mutuais, cooperativas de consumo, clubes musicais, escolas etc. ${ }^{65}$

A inspiração no modelo de corporação cristã de Harmel é muito clara, contudo, Menezes não parou aí. Ampliou a ambição de ação associativa ao criar, em 1902, a principal delas, Federação Operária Cristã, que ganhou proeminência para além dos domínios de Camaragibe. A Federação Operária Cristã expandiu suas atividades para os estados vizinhos e suas ações frequentemente confrontavam as organizações socialistas e anarquistas nos anos subsequentes, o que indica real disputa por influência sobre os trabalhadores.

Carlos Alberto de Menezes, com o objetivo de entender a situação dos operários em bases empíricas, criou o Grupo de Estudos Sociais, que empreendeu levantamentos sobre salários e condições de trabalho, custo de vida e quantificação do número de desempregados nas regiões industriais pernambucanas. O Grupo de Estudos Sociais foi também espaço para Menezes proferir palestras sobre catolicismo social e, especialmente, elaborar o anteprojeto da primeira lei brasileira sobre sindicatos e cooperativas. Fica nítida, mais uma vez, a tentativa de transferência do modelo de Léon Harmel, que participou da criação dos Cercles Chrétiens d'Études Sociales, em 1893. Apesar dessa inspiração, contudo, o Grupo de Estudos Sociais brasileiros tomou uma direção mais propositiva, na medida em que se concentrou em pesquisas sobre as condições de trabalho e em propostas para resolução dos problemas. Foi mais propositivo, pois além de ser espaço de formação social com bases católicas, como fora o grupo francês, elaborou um projeto de lei para regular a atividade de sindicatos e cooperativas e obteve sucesso em sua

65 CORPORATION Chrétienne du Val-des-Bois. Statuts: Imprimière Coopérative de Reims. Reims, FR: 1885. p. 2-3 (Bibliotheek Stichting de Bethune); CORPORAÇÃO Operária de Camaragibe. Estatutos. Recife, 1900. 
aprovação. Nesse sentido, apresentou uma proposta objetiva de intervenção na questão social por meio da adaptação do modelo francês à experiência brasileira.

Carlos Alberto de Menezes, tal qual Harmel na França, foi destacado líder católico brasileiro, organizador de congressos católicos, entre eles o $1^{\circ}$ Congresso Católico Brasileiro, realizado em Salvador, em 1900. Menezes tomou Harmel como exemplo e fez de sua obra uma continuação da experiência europeia no Brasil. Há casos de experiências claramente inspiradas no laboratório social de Harmel em outros países. ${ }^{66}$ Nada obstante, não há historiografia conhecida sobre essas experiências e, no caso aqui em análise, da interação entre Menezes a Harmel, em 1891, decorreu uma transferência de modelos de ação social que foi recriado em uma realidade distinta. $O$ associativismo confessional nos mundos do trabalho e as corporações cristãs são parte da experiência de trabalhadores brasileiros em outras localidades e o caso de Camaragibe teve primazia no período republicano. ${ }^{67}$

A interação entre Harmel e Menezes não terminou em 1891. Há registros de correspondências entre os dois por vários anos, às quais não tive acesso. ${ }^{68} \mathrm{~A}$ existência de vários panfletos, estatutos, prospectos, livros e outros materiais sobre o associativismo confessional francês na Coleção Carlos Alberto de Menezes também é indício dessa transferência de conceitos de ação social confessional. Ademais, a continuidade da interação entre a Corporation Chrétienne du Val-desBois e a Corporação Operária de Camaragibe, após a morte de Menezes, demonstra a força dessa conexão transnacional. Como já citado, após a morte de Menezes, seu genro, Pierre Collier, assumiu a direção tanto dos negócios quanto da militância católica. O periódico Les Échos de Val-des-Bois, da Corporation Chrétienne du Valdes-Bois, publicou cópias de várias correspondências trocadas com a congênere de Camaragibe pelo menos até 1911, o que demonstra a continuidade dessa relação e, ainda, que Menezes criou bases para um tipo de associativismo católico bastante específico e que tinha o patrocínio dos patrões.

66 TRIMOUILLE, op. cit., p. 153. Cita casos no Canadá e na Espanha.

67 Cidades como Belo Horizonte, São Paulo e Fortaleza, por exemplo, experimentaram 0 associativismo confessional sólido na Primeira República. AMARAL, op. cit., 2018; FARIAS, Damião Duque de. Em defesa da ordem. São Paulo: Hucitec, 1998; LIMA, Ana Cristina P. Obreiros pacíficos: (Fortaleza, 1915-1930). 2009. 199f. Dissertação (Mestrado em História) - Universidade Federal do Ceará, Fortaleza, 2009.

68 Pierre Trimouille cita tais correspondências, referenciadas em um dossiê organizado pelo padre Georges Guitton, que biografou Harmel na década de 1920, e que se encontra guardado na Biblioteca Nacional Francesa. Ao pesquisar este dossiê, contudo, não encontrei as cartas. 


\section{Notas sobre o paternalismo}

Apesar de não ser objeto específico deste artigo, que se ocupa principalmente das interações transnacionais entre duas experiências históricos e a transferência de modelos de ação social, creio que é preciso dedicar algumas palavras à questão do paternalismo da ação dos leigos católicos juntos aos operários. Em Pernambuco, observa-se um paternalismo acentuado no que se refere ao tipo de associativismo confessional que se conformou. Historiadores e cientistas sociais têm dado destaque para a incompatibilidade entre as estratégias de dominação patronal e a agency dos trabalhadores, ou mesmo para a "imobilização da força de trabalho pela moradia"69, que este tipo de configuração das relações de trabalho força. Historiadores vinculados à história social do trabalho no Brasil já salientaram que, mesmo em situações de extrema opressão, como em regime de escravidão, por exemplo, trabalhadores desafiavam e negociavam com o paternalismo senhorial e demonstravam resistência. ${ }^{70}$ Edward P. Thompson, um dos historiadores canônicos da história social, já argumentou que a análise da opressão aos trabalhadores pela chave do paternalismo mascara a agency dos trabalhadores, sugerindo muito frequentemente a manipulação. ${ }^{71}$

Apesar dos bons argumentos das análises que enfatizam a manipulação e o controle por meio da administração paternalista das fábricas, cabe destacar também algumas questões específicas que esse tipo de organização do trabalho apresenta. A construção da Fábrica de Tecidos de Camaragibe, no final do século XIX, significou a instalação de uma grande indústria em uma região do país que se encontrava em processo de industrialização, algo que a historiografia raramente dá destaque. Embora a região tivesse histórico de organizações de trabalhadores, especialmente em sociedades mutuais de artesãos em Recife ${ }^{72}$, é possível conjecturar que o patrocínio de Menezes em Camaragibe ajudou a introduzir para aqueles trabalhadores conceitos de associativismo, sindicalismo, mutualidade, seguridade social e legislação trabalhista. Se é verdade que o paternalismo dificulta a luta de trabalhadores contra a opressão de seus patrões, de forma geral, é também verdade que há outros aspectos a serem entendidos nessa relação. Em situações específicas

69 LOPES, op. cit.

70 LARA, S. H. Blowing in the Wind: E. P. Thompson e a experiência negra no Brasil. Projeto História Revista do Programa de Estudos Pós-graduados de História, São Paulo, n. 12, 1995; REIS, J. J. Rebelião escrava no Brasil: a história do levante dos Malês, 1835. São Paulo: Companhia das Letras, 2003; CHALHOUB, op. cit.

71 THOMPSON, E. P. Patrícios e plebeus. In: THOMPSON, E. P.. Costumes em comum. São Paulo: Companhia das Letras, 1998. p. 29-30.

72 MAC CORD, 2012, op. cit. 
como está em análise, a introdução de conceitos de direitos do trabalho, seguridade social e organização dos trabalhadores pode ter sido útil para a conformação de uma cultura política, mesmo que em bases conservadoras e guiadas pela moral cristã. Cabe destacar que os trabalhadores de Camaragibe possuíam uma estrutura complexa de proteção ao trabalho, com cooperativas e sociedades mutuais desde o início da operação da fábrica, enquanto trabalhadores de outras regiões do Brasil, mesmo as mais industrializadas, como São Paulo e Rio de Janeiro, tinham dificuldades em constituir sociedades mutuais longevas. ${ }^{73}$

Tal relação paternalista torna-se mais complexa na medida em que o associativismo se dava também no interior das vilas operárias. Acentua-se essa complexidade quando se considera o caráter confessional do associativismo, que envolve também questões de ordem espiritual, relativas à fé, portanto, de difícil mensuração objetiva. O modelo que serviu de exemplo para Carlos Alberto de Menezes foi o da patronnage francesa, do bon patron. ${ }^{74}$ Embora os textos de Léon Harmel aos quais Menezes teve acesso (e possivelmente as correspondências que trocaram) já apontassem a intenção de incentivar o associativismo livre dos trabalhadores católicos, a Federação Operária Cristã oferecia um guia da ação social católica para operários, mas foi dirigida primeiro pelo próprio Carlos Alberto de Menezes e, posteriormente, por Pierre Collier, ambos patrões. Apesar da participação dos trabalhadores nos conselhos de gestão da fábrica e das organizações, Menezes, até 1904, e Pierre Collier, pelo menos até 1914, lideravam a Corporação Operária de Camaragibe e a Federação Operária Cristã.

Não há indicação nas fontes às quais tive acesso de que Menezes tenha tido ciência da decisão tomada por Harmel, em 1903, de se afastar da vida associativa dos operários, deixando-os decidir livremente sobre os caminhos de seu movimento. É sabido que Menezes entrou no século XX doente. Em 1901, esteve na França em busca de tratamento médico. ${ }^{75}$ Embora tenha permanecido ativo na indústria e na Federação Operária Cristã até sua morte, em 1904, é possível que não tenha conhecido a decisão de Harmel, tomada um ano antes. A liderança de Collier nos anos subsequentes indica a continuidade da centralidade do patrão nas atividades associativas.

73 Claudio Batalha destaca a efemeridade de sindicatos e mutuais na cidade do Rio de Janeiro. Ver: BATALHA, Claudio (org). Dicionário do movimento operário na cidade do Rio de Janeiro do século XIX aos anos 1920: militantes e organizações. São Paulo: Fundação Perseu Abramo, 2009.

74 A cultura do bon patron francês durante o século XIX e sua difusão pela Europa são analisadas por HEYRMAN, op. cit., p. 163-186.

75 Foi também, nessa ocasião, que Menezes reencontrou com o padre. Déhon na França. Léon Déhon.

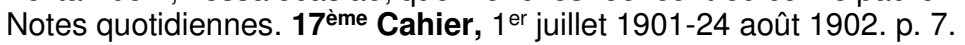




\section{Considerações finais}

A publicação da encíclica Rerum Novarum, em 1891, desencadeou a ação de católicos leigos direcionada à questão social em todo o mundo cristão. ${ }^{76} \mathrm{~A}$ carta de Leão XIII foi a formalização de uma doutrina que fora gestada pela ação de clérigos e de leigos nas décadas anteriores. A atuação de Carlos Alberto de Menezes tem raízes anteriores à própria formalização da doutrina social da Igreja. Menezes assim como Léon Harmel - foi sujeito da formação de um catolicismo militante anterior à publicação da mais famosa carta do papa Leão XIII e, igualmente, de sua difusão posterior. Nesse sentido, sua militância é parte de processo histórico pelo qual o catolicismo se colocou como uma opção de organização social para os trabalhadores.

De Val-des-Bois a Camaragibe, iniciado por uma ação patrocinada por elites católicas leigas, o catolicismo social converteu-se em uma cultura militante que ganhou corações e mentes de trabalhadores. Na história da organização dos trabalhadores brasileiros, são conhecidos casos em que, nas décadas seguintes, havia a presença da militância católica em sindicatos. A própria legislação social brasileira e, sobretudo, o discurso das lideranças políticas direcionado aos trabalhadores, frequentemente evocou princípios cristãos da ordem social e da disciplina para o trabalho. Comumente, a ação social dos católicos nos mundos do trabalho é tratada como consequência de uma ação institucional da Igreja, após a publicação da encíclica Rerum Novarum, em 1891. A interação entre Carlos Alberto de Menezes e Léon Harmel e o consequente associativismo católico nos moldes da corporação cristã em Pernambuco mostram que o processo de conformação do associativismo confessional no Brasil é muito mais complexo e não está forçosamente vinculado à ação institucional da Igreja católica no Brasil.

Recebido em 26/08/2019

Aprovado em 10/09/2019

76 ANDES, Stephen; YOUNG, Julia. Local church, global church: catholic activism in Latin America from Rerum Novarum to Vatican II. Washington: Catholic University of America Press, 2016. 